\title{
O PRINCÍPIO DA ICONICIDADE $\in$ SUA ATUAÇÃO NO PORTUGUÊS DO BRASIL
}

\author{
Maria Célia Lima-Hernandes*
}

RESUMO: ESte artigo apresenta um resgate do princípio da iconicidade por meio do exame de estudos que dele fizeram uso como critério de análise e como explicação funcional para o comportamento de fenômenos gramaticais.

PALAVRAS-CHAVE: Funcionalismo; Iconicidade; Português brasileiro.

INTRODUÇÃO

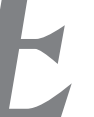

proposta deste artigo o estudo do princípio da iconicidade e a análise do aproveitamento que dele fazem pesquisadores para explicar fenômenos ocorrentes nas línguas, em especial no português do Brasil.

Na verdade, encontra-se um vácuo teórico na literatura especializada e bases pouco seguras quanto à definição desse princípio.

Dessa maneira, estabelece-se uma comparação entre as várias associações que remetem à iconicidade enquanto princípio linguiístico e discutem-se suas formas de manifestação no português do Brasil.

O texto encontra-se estruturado em três partes. Na primeira, discutimos a origem do princípio da iconicidade e sua conceituação por lingüistas; na segunda, apresentamos a análise de dois estu-

Universidade de São Paulo. 
LIMA-HERNANDES, Maria Célia. O princípio da iconicidade e sua atuação no português...

dos (Braga, 1996 e Mollica, 1998), que conferem a esse princípio uma forte atuação nos fenômenos investigados. Por fim, na terceira parte, apresentamos comentários finais e discussão sobre perspectivas de estudos.

\section{CONTROVÉRSIAS E INCOMPLETUDES: A FALTA DE CONSENSO?!}

É idéia neutra entre os funcionalistas que o princípio da iconicidade prevê uma relação motivadora unívoca entre forma e função, sendo que a primeira determina a segunda, nunca o inverso. Para alguns linguiistas (Votre, 1982), enclausurar nessa definição o que seja iconicidade denota uma visão radicalizada que impediria o reconhecimento de outras manifestações.

\section{1 E do ícone, um princípio..}

O signo icônico é oriundo da terminologia peirceana e sobrevive invariavelmente ligado à área da semiótica, entretanto, tem assumido papel, se não relevante, ao menos de destaque, na Sociolinguiística e na Gramática Funcional.

Na visão de Peirce, há que se levar em conta a distinção entre as relações signo $\mathrm{x}$ objeto representadas por três elementos: ícone, índice e símbolo. O ícone representa, originalmente, a relação de semelhança estabelecida entre o signo e a realidade exterior; o índice, a relação de contigüidade; e o símbolo, a relação convencional.

Uma vez que, no signo icônico, ao contrário do que ocorre no signo saussureano, há uma relação motivada, funcionalistas e sociolingüistas têm aproveitado o conceito de iconicidade para além dos domínios sígnicos. Aparece, agora, tanto relacionado a elementos menores do que o signo - como ocorre com os morfemas quanto a elementos maiores - como ocorre com as sentenças complexas. 
Filol. lingüíst. port., n. 8, p. 83-96, 2006.

Em Greenberg (1966, apud Dik, 1997, p. 133), há expressa a noção básica do princípio da iconicidade linguiística, tal como concebem os funcionalistas atualmente. $\mathrm{O}$ autor indica, naquele artigo, a ordem dos elementos na língua como fruto da ordem de conhecimentos decorrentes da experiência física.

Segundo Dik (1997), ${ }^{1}$ alguns psicolingüistas atribuem tal paralelismo entre estrutura linguiística e ordenação dos fatos no mundo real a um princípio chamado "ordem de menção" e justificam que a esse princípio estaria condicionada a compreensão das crianças de 3 a 5 anos de idade. É, portanto, pressuposto básico desse princípio que a ordenação linear respeita a ordem de acontecimento dos fatos.

Não há dúvidas de que esses psicolingüistas referem-se ao mesmo princípio de iconicidade tratado por lingüistas, que determinaria, inclusive, a ordenação sintática das orações. Assim, "orações devem preferencialmente ser ordenadas segundo as relações conceptivas ou temporais, decorrentes dos fatos ou estados de coisa que designam" (Dik, 1997, p. 134). Exemplo adequado para essa ordenação lógica seria antepor uma oração de causa precedendo a oração codificadora do efeito.

\subsection{Edo princípio, subprincípios..}

Haiman (1983, p. 782-3) discute a iconicidade e suas motivações com base em três afirmações:

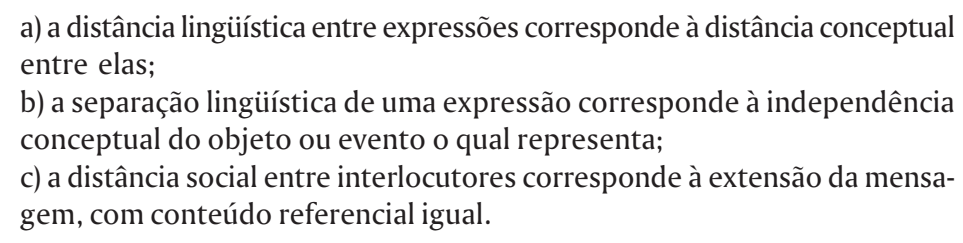

1 Dik cita como referência os trabalhos de Clark $(1971,1977)$. 
LIMA-HERNANDES, Maria Célia. O princípio da iconicidade e sua atuação no português...

Essas afirmações podem ser enquadradas em três motivações: por distância conceptual, por individuação e por distância social. A primeira atuaria em categorias de causa, ordenação, transitividade e posse as quais manteriam um paralelismo formal entre distância conceptual e formal. A segunda refere-se ao paralelismo entre independência conceptual e independência formal. A terceira é flagrada na distância física e suas relações paralelas com a distância social, tanto instrumental quanto referencial.

Por ser princípio geral, a iconicidade aparece como explicação parcial para vários fenômenos linguiísticos, como ocorre com a continuidade tópica discursiva (Givón, 1983, p. 18): "the more disruptive, surprising, discontinuous or hard to process a topic is, the more coding material must be assigned to it."

Na literatura linguiística atual, três trabalhos (Votre, 1992; Neves, 1997; Votre et al., 1999) resumem, de forma bastante clara, as várias manifestações da iconicidade, as quais podem ser encontradas tanto com o rótulo de subprincípios, no primeiro e no terceiro trabalhos, quanto com o rótulo de tipologia, no segundo trabalho. Não é objetivo deste estudo a discussão terminológica, razão pela qual nos deteremos em focalizar a iconicidade nas estruturas linguiísticas.

Para Votre (1992) e Votre et al. (1999), os seguintes subprincípios podem manifestar a iconicidade: quantidade, proximidade espaçotemporal e ordenação espaço-temporal. Com a atuação do primeiro, subprincípio da quantidade, seriam desencadeadores de forma maior a informação maior, a imprevisibilidade da informação e a importância para a continuidade temática. Com a atuação do segundo, subprincípio da proximidade, é observada a estreiteza de relação existente, quanto à distância, entre expressões na cadeia da frase ou unidades textuais maiores do que frase e pode ser observada no maior grau de integração morfossintática e de liberdade entre os constituintes. Com a atuação do terceiro, subprincípio da ordenação linear, informações mais importantes, mais previsíveis e imprescindíveis para assegurar a cadeia aparecem em primeiro lugar. 
Filol. lingüíst. port., n. 8, p. 83-96, 2006.

Com base em Haiman $(1983,1985)$ e Newmeyer (1992), Neves apresenta vários tipos de iconicidade:

a) Iconicidade de quantidade: quanto maior a informação, maior a forma;

b) Iconicidade de distância ou proximidade: quanto maior a distância conceptual, maior a distância linguiística entre expressões;

c) Iconicidade de independência: separação linguiística de expressão $\rightarrow$ independência conceptual;

d) Iconicidade de ordenação: grau de importância determina a ordem;

e) Iconicidade de complexidade: forma plural maior do que forma singular;

f) Iconicidade de categorização: sujeitos são preponderantemente agentes e objetos, pacientes.

Neves (1997, p. 109) conclui que não é simples argumentar a favor da iconicidade, uma vez que a estrutura analisada (significado) está sempre por se estabelecer. Como argumento, lança mão do contra-exemplo também apresentado por Haiman: as não-icônicas e pouco econômicas formas sinonímicas.

Com base no exposto, podemos estabelecer uma comparação entre os dois autores, quanto à interpretação do princípio da iconicidade e sua atuação. Como resultado dessa comparação, compusemos um quadro que revela algumas discordâncias, pelo menos no que toca à área de atuação mais específica de alguns subprincípios. 
LIMA-HERNANDES, Maria Célia. O princípio da iconicidade e sua atuação no português...

\begin{tabular}{|l|l|l|}
\hline \multicolumn{1}{|c|}{ Subprincípio } & \multicolumn{1}{|c|}{ Votre (1999) } & \multicolumn{1}{c|}{ Neves (1997) } \\
\hline Categorização & & $\begin{array}{l}\text { > Sujeito: [+agente] } \\
\text { > Objeto: [+paciente] }\end{array}$ \\
\hline Complexidade & $\begin{array}{l}\text { > A forma plural é maior do que a } \\
\text { singular } \\
\text { > A forma superlativa é maior do } \\
\text { que a normal }\end{array}$ \\
\hline Independência & $\begin{array}{l}\text { > Separação conceptual traduz-se } \\
\text { lingüisticamente na separação entre } \\
\text { expressões. }\end{array}$ \\
\hline Ordenação & $\begin{array}{l}\text { > Informação +previsível, } \\
\text { +importante para cadeia } \\
\text { apresenta-se em primeiro lugar. }\end{array}$ & $\begin{array}{l}\text { > Maior grau de integração } \\
\text { morfossintática } \\
\text { > Liberdade entre constituintes. }\end{array}$ \\
\hline $\begin{array}{l}\text { Proximidade } \\
\text { ou }\end{array}$ & $\begin{array}{l}\text { Puanto maior a distância } \\
\text { conceptual, maior a distância } \\
\text { lingüística }\end{array}$ \\
\hline Quantidade & $\begin{array}{l}\text { Maior forma, imprevisibilidade } \\
\text { da informação e importância na } \\
\text { continuidade temática: maior }\end{array}$ & $\begin{array}{l}\text { > Quanto maior a informação, } \\
\text { maior a forma. }\end{array}$ \\
\hline
\end{tabular}

Votre et al. (1999) não reconhecem os subprincípios categorização, complexidade e independência como autônomos, ao contrário do que faz Neves (1997), provavelmente porque, no subprincípio da proximidade, já esteja inserida a idéia de categorização das palavras, de independência, refletida pela liberdade entre constituintes, e de complexidade - observável por meio do grau de integração entre termos e sentenças.

A aplicação e o reconhecimento desses subprincípios em estruturas linguí́sticas estão longe de ser uma tarefa mecânica, porque há forças que podem atuar ao par da motivação icônica, resultando num aparente paradoxo. É dessa maneira que, por exemplo, informações menos previsíveis, menos importantes e menos acessíveis, ao contrário do que se esperaria, podem aparecer em primeiro lugar, caso a cadeia tópica detenha o traço [+contraste].

Contudo, essa idéia não se traduz em novidade. Informação similar pode ser observada no trabalho de Francis (1998, p. 412):

Structure-discourse iconicity is, in any utterance where it is found, the result of the interaction of multiple factors. At the very least, these factors must include conventional semantic content of individual linguistic elements and discourse-functional pressures. 
Filol. lingüíst. port., n. 8, p. 83-96, 2006.

Com as informações assim sistematizadas, parece que toda dúvida se dissipa e que a conceituação de iconicidade seja, de fato, mais simples do que inicialmente supúnhamos. Isso posto, teremos condições de analisar dois trabalhos, apresentados sinteticamente na próxima seção. Ambos fizeram uso do princípio da iconicidade para explicar fenômenos sintáticos do português do Brasil.

\section{A ICONICIDADE NO PORTUGUÊS DO BRASIL}

O princípio da iconicidade tem se manifestado como um verdadeiro oásis em muitos estudos descritivos de fenômenos aparentemente desérticos (Mollica, 1995, 1998; Pezatti, 1996; Oliveira, 1996; dentre outros) e, ao mesmo tempo, para outros linguiistas, tem se manifestado como uma verdadeira miragem que mostra um caminho ideal ao lado de condicionamentos reais (Braga, 1995, 1996; Lima-Hernandes, 1998; Neves \& Braga, 1998).

Num estágio mais concreto, mais evidente e, portanto, mais acessível à compreensão, está a iconicidade temporal que prevê, na representação linguiística de determinados eventos, o gerenciamento da ordem linguística pela ordem dos acontecimentos no mundo real.

Iconicidade, porém, não se resume tão-somente à ordenação temporal. Outros fenômenos abarcam em sua existência traços icônicos. Exemplo disso seria a semântica diacrônica de plicare $>$ chegar, determinada pela pragmática e matizada pela iconicidade.

Na verdade, vemos um campo muito grande de associações a esse princípio. Aqui, discutiremos dois trabalhos e o aproveitamento que cada um faz da iconicidade.

\subsection{1 dos subprincípios, fenômenos motivados...}

Com base no princípio da iconicidade, Braga (1996) e Mollica (1998) tecem, respectivamente, algumas explicações sobre o com- 
portamento das orações reduzidas de gerúndio e do dequeísmo no português do Brasil.

Braga desenvolve, há alguns anos, pesquisas sobre as orações de tempo e, em trabalho de 1995, divulgou resultados surpreendentes sobre o comportamento dessas orações, chegando à conclusão de que as reduzidas seriam orações a meio caminho das demais analisadas, uma vez que possuíam mobilidade posicional como as desenvolvidas e sujeitos cancelados em índices similares ao das coordenadas.

Por revelarem-se ambíguas, Braga (1996) retoma as orações reduzidas, desta vez colhendo-as no corpus do Projeto da Gramática do Português Falado, formado a partir de materiais de língua falada do Projeto Nurc. Era sua intenção detectar as motivações que favoreceriam o uso dessa estratégia. Para tanto, a autora elegeu quatro variáveis ligadas ao estatuto sintático desse tipo de oração: posição, explicitude do sujeito, identidade entre sujeitos e nível sintático do constituinte ao qual a oração se articula.

Os números a que chegou confirmaram os resultados prévios (Braga, 1995) quanto à posição da oração, uma vez que tanto desenvolvidas quanto reduzidas detinham mobilidade posicional, enquanto coordenadas eram categoricamente fixadas à margem esquerda.

Quanto à explicitude do sujeito, a taxa de [+identidade] entre sujeitos mostrou-se alta nas orações reduzidas. Esse fato explica a alta taxa de apagamento de sujeitos nesse tipo de oração, em que a integração com a oração-núcleo parece exibir o mais alto grau, sobretudo porque somente a partir da leitura de oração-núcleo pode-se inferir o tempo-modo da oração reduzida.

Mollica (1998) faz uma apresentação parcial de pesquisa realizada sobre dequeísmo no PB, fenômeno observado pela autora desde 1989. Nossa análise restringe-se tão somente ao texto de 1998 em que a autora afirma ser a iconicidade o princípio regulador do emprego da preposição 'de'.

Embora o trabalho citado como ponto de partida pela autora em seu artigo - Gomes (1997) - apresente, dentre os exemplos, estrutura condicionada pelo paralelismo, abstemo-nos de elaborar 
críticas mais profundas sobre o fato e a incluímos nesta resenha a título de referência.

Gomes (1997), também focalizando uso da preposição ‘de' com corpus do português de contato, atualmente integrado ao PEUL, chegou aos seguintes resultados correlacionados à fluência do falante: a) maior fluência: alto domínio no uso do sistema preposicional em contextos de uso categórico e variável; b) menor fluência: domínio incipiente no uso da preposição; e c) fluência intermediária: domínio ampliado no uso de preposições em contextos categóricos e início de uso em contextos variáveis.

Sua hipótese também é fundamentada em Haiman (1983), como ocorre com Mollica (1998), entretanto numa reformulação diferente sobre a teoria da transitividade. Enquanto Haiman explica a iconicidade na análise de verbos transitivos diretos e indiretos, a autora inclui a intransitividade: "a distância entre verbo transitivo e seu complemento é menor que a distância entre intransitivo e seu complemento" e conclui que o uso mais acentuado de preposições ocorre em função da transparência semântica conferida e do menor laço coesivo entre verbo e SN.

Por transparência, entenda-se saliência à percepção do falante no momento da fala; quer se referir aos casos em que 'gostar' e 'depender' têm uso categórico com preposição enquanto 'precisar', 'necessitar', lembrar' e 'esquecer' têm uso variável, cujos comportamentos seriam também tendências do português carioca.

Mollica (1998) investiga a hipótese de que o uso da preposição seja índice de não comprometimento do falante com o que diz. Em outras palavras, o dequeísmo marcaria a diminuição no grau de assertividade dos enunciados. Para checar tal hipótese, a autora seleciona o tipo do sujeito como variável independente, encontrando os seguintes resultados.

Três tipos de sujeitos estiveram presentes nas estruturas observadas: primeira pessoa, outras pessoas e sujeito impessoal. Seguindo o raciocínio da autora, a primeira pessoa evidencia o mais alto grau de assertividade e comprometimento; as outras pessoas 
indicariam o grau intermediário de comprometimento do falante; e o sujeito impessoal atingiria o mais alto grau de distanciamento, logo descomprometimento do falante.

As intuições de Mollica se confirmaram, haja vista que o sujeito impessoal alcançou o índice mais alto nos cálculos probabilísticos, ou seja, o distanciamento esteve correlacionado ao dequeísmo.

\section{3. $\in$ DOS FENÔMENOS MOTIVADOS, AS EXPLICAÇÕES...}

Sobressai dos estudos de Braga (1996) e Mollica (1998) o argumento central de que o princípio da iconicidade é refletido pela relação unívoca entre conteúdo e expressão.

Em Braga (1996), ocorre a redução e incorporação da oração pelo caráter 'subordinado' da informação contida na oração de gerúndio.

Num grau mais elevado de abstração linguiística, no plano conceptual, o princípio da iconicidade estaria atuando fortemente, haja vista que informações "pano de fundo" correspondem a estruturas subordinadas.

Por outro lado, se levamos em conta o subprincípio da ordenação linear, informações mais importantes, mais previsíveis e fundamentais para assegurar a cadeia aparecem em primeiro lugar. Olhando para os dados de Braga (1996), vemos que, no conjunto selecionado para análise há orações diferentes quanto à função, apesar de a forma assumida ser a mesma, o que nos permite elaborar a seguinte questão: seriam as orações analisadas ambíguas ou seriam tipos diferentes de orações? Partir da forma e ignorar a relação unívoca entre forma e função seria o percurso funcionalista?

Na verdade, sim. Os argumentos de Haiman elidem qualquer dúvida que possa pairar, pois, ainda que o ideal fosse uma forma para cada função, na prática isso seria inviável, porque muitas seriam as formas e um pesado trabalho de memorização para o falante/ouvinte seria necessário. 
Filol. lingüíst. port., n. 8, p. 83-96, 2006.

Por esse motivo, Haiman (1983) fala em relação motivada para forma/função, ou seja, a atuação de alguns subprincípios pode determinar a iconicidade entre conteúdo/expressão, como seria o distanciamento linguiístico provocado pelo distanciamento conceptual.

É este o momento em que todo linguiista se pergunta: seriam, no mundo linguiístico, as construções sintáticas determinadas por princípios do mundo real?

Para Saussure (1973), não; para Du Bois (1984), parcialmente; para Haiman (1980), em alguns casos motivados; e para Givón, totalmente.

Assim, tanto temos uma forma desempenhando várias funções quanto temos também um sentido encontrado em várias formas. Vários trabalhos funcionalistas recentes sobre o PB mostraram como isso funciona (Neves \& Braga, 1998; Lima-Hernandes, 1998; Galvão, 1998; dentre outros).

Afora os descuidos observados em Mollica (1998), os quais poderiam minar qualquer pesquisa científica, ainda temos a questão do aproveitamento do princípio da iconicidade como gerenciador do uso da preposição 'de'.

A validade da hipótese e da explicação oferecida é indiscutível, sobretudo porque, até mesmo na literatura mais tradicional, encontramos informações que a abonam.

Segundo Coutinho (1938, p. 315), a grande maioria das preposições latinas passaram para o português. Esse é o caso específico da preposição 'de', que aparece registrada em documentos já no século XIII.

Para Cegalla (1971), 'de' pode indicar causa, posse, matéria e origem e rege normalmente tanto as orações subordinadas substantivas objetivas indiretas quanto as completivas nominais, além de suprir a regência reclamada pelo verbo de uma oração subordinada adjetiva.

Cunha (1983, p. 386) complementa essas informações, afirmando que a preposição 'de' também pode indicar afastamento de um ponto, de um limite, no eixo espaço-tempo. Contudo, é Bechara 
(1992) quem traz as informações mais impregnadas de um respaldo empírico.

Bechara (1992, p. 312) discute casos em que uma simples migração de preposição dentro da sentença cause, como vemos nos exemplos (1) e (2), a reanálise da estrutura.

(1) Não sei o em que pensar > Não sei no que pensar

(2) o de que precisamos é braços valororos $>$ o que precisamos é de braços valorosos

Podemos notar que essa migração de preposição dentro da sentença gera um conflito de regências verbais. Casos desse tipo mereceriam uma investigação mais profunda que levasse em conta não só o estatuto diacrônico, mas também o estatuto gerativo da sentença, haja vista as seguintes afirmações do autor: a) construções desse tipo são muito comuns atualmente; e b) todos os contraexemplos, numa estrutura regular, são tidos pelos usuários da língua como estratégias artificiais (p. 272).

Por outro lado, uma abordagem semântica do verbo também é imprescindível, pois, quando Bechara (p. 290) afirma que 'de' não ocorre junto a verbos e a adjetivos que tragam como bagagem semântica a noção de afastamento ou de diferença, ficamos a pensar em quais condicionamentos estariam atuando para o exílio prepositivo.

Mas, se, para Mollica (1998), a iconicidade apresenta-se como o oásis que traz, como a fonte desejada, a solução para um problema e, para Braga (1996), como a descoberta de forças em competição que mais tumultuam do que aclaram a leitura do fenômeno, ao nosso ver a questão volta à estaca zero.

Urge, portanto, que uma detida análise teórica do fato se realize, levando-se em conta a existência de um princípio, que, por definição, deva ser [+geral], [+abstrato], [+autônomo], mas que, em sua interface com o domínio discursivo-pragmático, assume outros traços, advindos do contexto: [-geral], [-abstrato] e [-autônomo]. 
Filol. lingüíst. port., n. 8, p. 83-96, 2006.

\section{BIBLIOGRAFIA}

BECHARA, E. (1992). Moderna Gramática Portuguesa. São Paulo: Nacional.

BRAGA, M. L.(1996). Processos de redução: o caso das orações de gerúndio. In: KOCH, I. G. V. (Org.). Gramática do Português Falado. Volume VI: Desenvolvimentos. Campinas/São Paulo: Ed. Unicamp/Fapesp, p. 231-51.

. (1995). As orações de tempo no discurso oral. In: Cadernos de Estudos lingüísticos (28). Campinas: IEL/Unicamp, p. 85-97.

CEGAllA, D. P. (1971). Novíssima Gramática da Língua Portuguesa. São Paulo: Nacional.

COUTINHO, I. L. (1962). Pontos de Gramática Histórica. Rio de Janeiro: Acadêmica.

CUNHA, C. (1983). Gramática do Português Contemporâneo. Rio de Janeiro: Padrão.

DIK, S. C. (1997). The theory of functional grammar. Part 2:Complex and derived constructions. Berlim/Nova Iorque, Mouton de Gruyter, p. 133-7; 435-6.

DU BOIS, J. W. (1984). Competing Motivations. In: HAIMAN, J. Iconicity in syntax. Amsterdam, John Benjamins, pp. 343-65.

FRANCIS, E.J. (1998). Some Semantic reasons why iconicity between lexical categories and theirdiscourse functions isn't perfect. Language (20), p. 399-414.

GIVÓN, T. (Ed.) (1983). Topic continuity in discourse: a quantitative cross-language study. Amsterdam / Philadelphia: John Benjamins Publishing.

GOMES, C. A. (1997). Processos variáveis de aquisição de preposição. In: RONCARATI, C. \& M. C. MOLLICA. (Orgs.). Variação e Aquisição. Rio de Janeiro: Tempo Brasileiro.

HAIMAN, J. (1983). Iconic and economic motivation. Language (59), Baltimore: Waverly Press.

LIMA-HERNANDES, M. C. P. (1998). Gramaticalização de combinação de cláusulas: orações de tempo no português do Brasil. Dissertação de Mestrado. São Paulo, USP.

MOLLICA, M. C. (1998). Mecanismos de indeterminação do sistema preposicional. In: GROBE, S. \& ZIMMERMANN, K. (Ed.) Frankfurt am Main:TFM, p. 357-69. . (1995). (De) que falamos? Rio de Janeiro: Tempo Brasileiro.

NEVES, M. H. M. (1997). A gramática funcional. São Paulo: Martins Fontes.

. \& BRAGA, M. L. (1998). Hipotaxe e Gramaticalização: uma análise das construções de tempo e de condição. Delta.

OLIVEIRA, M. R.de. (1996). Gramaticalização na repetição. In: MARTELLOTA, M. E. et al. (Orgs.) Gramaticalização no Português do Brasil: uma abordagem funcional. Rio de Janeiro: Tempo Brasileiro.

PEZATTI, E. G. (1996). Estrutura argumental e fluxo de informação. In: KOCH, I. G. V. (Org.) Gramática do Português Falado. Volume VI:Desenvolvimentos. Campinas/São Paulo: Ed. Unicamp/ Fapesp, p. 275-99.

VOTRE, S. J. (1992). Lingüística funcional: teoria e prática. Rio de Janeiro: UFRJ, mimeo. et al. (1999). Dicionário básico de Lingüística Funcional. Rio de Janeiro: inédito. 
LIMA-HERNANDES, Maria Célia. O princípio da iconicidade e sua atuação no português...

ABSTRACT: This paper presents an overview of the iconicity principle through examination of studies that employ this principle was included as a criterion for observation and as a functional expression of the behavior of grammatical phenomena.

KEYWORDS: Functionalism; Iconicity; Brazilian Portuguese. 